\title{
Excess in the pharmaceutical industry
}

\section{Marcia Angell}

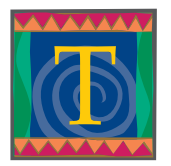

he main point about excess in the pharmaceutical industry is how much there is of it. Here I can touch on only a few specifics about this altogether over-the-top business.

\section{Profits}

Although the pharmaceutical industry claims to be a high-risk business, year after year drug companies enjoy higher profits than any other industry. In 2002, for example, the top 10 drug companies in the United States had a median profit margin of $17 \%$, compared with only $3.1 \%$ for all the other industries on the Fortune 500 list. ${ }^{1}$ Indeed, subtracting losses from gains, those 10 companies made more in profits that year than the other 490 companies put together. Pfizer, the world's number-one drug company, had a profit margin of $26 \%$ of sales. In 2003, for the first time in over 2 decades, the pharmaceutical industry fell slightly from its number-one spot to third, but this was explained by special circumstances, including Pfizer's purchase of another drug giant, Pharmacia, which cut into its profits for the year. The industry's profits were still an extraordinary $14 \%$ of sales, well above the median of $4.6 \%$ for other industries. ${ }^{2} \mathrm{~A}$ business that is consistently so profitable can hardly be considered risky.

Excess profits are, of course, the result of excess prices - and prices are excessive principally in the United States, the only advanced country that does not limit pharmaceutical price increases in some way. Of the top 10 drug companies in the world, 5 are European and 5 are American, but all of them have the US as their major profit centre. In the US, uninsured patients (of which there are many) are charged more for drugs than those who have large insurance companies to bargain for them, and the prices of prescription drugs are generally much higher to start with than in other advanced countries. Moreover, the prices of topselling drugs are routinely jacked up in the US at 2 to 3 times the general rate of inflation. . $^{1,34}$

\section{"Me-too" drugs}

The main output of the big drug companies is "me-too" drugs: minor variations of highly profitable pharmaceuticals already on the market. ${ }^{5}$ Some me-too drugs are gimmicks to extend monopoly rights on an older blockbuster. For example, the antacid Nexium was AstraZeneca's virtually identical replacement for Prilosec when its exclusive rights on the

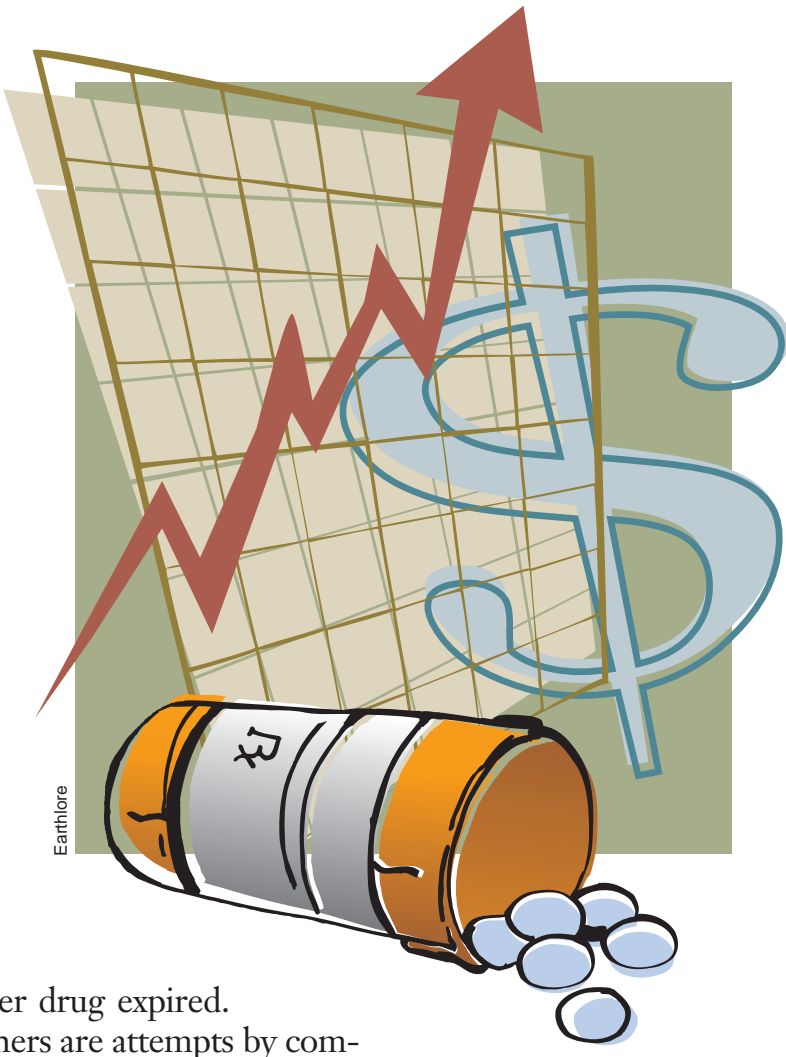

Others are attempts by com-

petitors to cash in on lucrative mar-

kets. For example, the top-selling drug in the world, Pfizer's Lipitor, is the third of 3 me-too drugs to cash in on the success of the first statin, Merck's Mevacor. All of these drugs inhibit the same rate-limiting enzyme in cholesterol synthesis. There is generally no good reason to believe that one me-too drug is better than another, since they are seldom compared head-to-head at equivalent doses in clinical trials. Instead, they are tested against placebo, and so all we know is that they are better than nothing. In fact, it's conceivable that, within me-too families, each successive drug is actually worse than the one before. Without suitable comparative testing, we'll never know.

Because me-too drugs are cheaper and less risky to develop and have ready-made markets, the industry increasingly relies on them. From 1998 through 2003, 487 drugs were approved by the US Food and Drug Administration (FDA). Of those, 379 (78\%) were classified by the agency as "appear[ing] to have therapeutic qualities similar to those of one or more already marketed drugs," and 333 (68\%) weren't even new compounds (what the FDA calls "new molecular entities"), but instead were new formulations or combinations of old ones. Only 67 (14\%) of the 487 were 
actually new compounds considered likely to be improvements over older drugs. ${ }^{5}$

This state of affairs is growing worse. The industry justifies me-too drugs by arguing that they provide back-up for patients who don't respond well to already available drugs and that the competition keeps prices down. Neither argument has much merit. The claim that back-up me-too drugs are clinically useful is rarely tested in trials. Drug companies don't test their me-too drugs in people who haven't responded to another drug (or have had unacceptable side-effects). Anecdotes, of which there are plenty, are notoriously unreliable. In any case, while it may be reasonable to have 1 back-up available, it's hard to make the case for 4,6 or 8 .

As for price competition, there is very little of it. Me-too drugs are almost never promoted as being cheaper than the others. Instead, companies imply that they are better in some way. Sometimes they do this by touting the results of clinical trials in which the drug was used for a slightly different indication. (These and other kinds of phase IV or post-approval studies consume about a quarter of the industry's much-vaunted R\&D [research and development] expenditures. ${ }^{\circ}$ ) But the fact remains that in the US the prices of drugs in most me-too categories are almost never reduced over time, despite the introduction of new competitors. Instead, prices are relentlessly increased.

\section{Marketing}

Closely tied to excess me-too drugs are excessive marketing expenditures. For decades, the big drug companies have spent far more on "marketing and administration" (companies have slightly different names for this budgetary item) than on anything else. Throughout the 1990s, for example, the top 10 drug companies in the world consistently spent about $35 \%$ of sales on marketing and administration, and only $11 \%$ to $14 \%$ on R\&D. ${ }^{7}$ (For that decade, they took in profits of $19 \%$ to $25 \%$ of sales.) Just looking at the top 10 US companies in 2002, expenditures for marketing and administration were 31\% of sales, compared with only $14 \%$ for R\&D. ${ }^{1}$ That comes to an astonishing $\$ 67$ billion dollars of their $\$ 217$ billion in sales.

Where did all that money go? No one can say for sure, because the drug companies do not make that information publicly available. But one can make some reasonable estimates. First, the lion's share probably went to marketing, not administration. That assumption is supported by the fact that, according to the Pharmaceutical Research and Manufacturers of America (PhRMA), the industry's trade association, $35 \%$ of its members' personnel in 2000 were in marketing, compared with $12 \%$ in administration. ${ }^{6}$ Marketing includes expenditures for "education of medical professionals," which is probably the biggest single chunk of it. Administration includes executive salaries (which are huge ${ }^{8}$ ), legal costs and the overhead associated with run- ning any large business.

Most marketing is directed toward persuading doctors and patients to choose one me-too drug over another, usually without a scientific basis for doing so. For that reason, free samples are mainly newly patented, me-too drugs. It takes a lot of promotion to convince people to select one me-too drug over another. AstraZeneca was reported to have spent a half-billion dollars in a year to switch Prilosec users to Nexium. ${ }^{9}$ In contrast, a uniquely important drug would require very little promotion.

Advertising also expands the total market. Drug companies increasingly promote diseases to fit drugs, rather than the reverse. They try to persuade people in affluent countries that they are suffering from conditions that need long-term treatment. Thus, millions of normal people come to believe that they have dubious or exaggerated ailments such as "generalized anxiety disorder," "erectile dysfunction," "premenstrual dysphoric disorder" and GERD (gastroesophageal reflux disease). That, too, is expensive.

The big drug companies like to say that prices have to be high to cover their $R \& D$ costs, but it would be truer to say they are high to cover their marketing costs - and their outsize profits.

\section{Influence on the medical profession}

The medical profession has largely abdicated its responsibility to educate medical students and doctors in the use of prescription drugs. Drug companies now support most continuing medical education, medical conferences and meetings of professional associations. ${ }^{10} \mathrm{Al}-$ though they call it education, the billions of dollars they put into it comes out of their marketing budgets. The industry also provides students, house officers and physicians in practice with meals, trips to exotic locations and many other blandishments. Although medical and industry associations have issued guidelines that would limit these gifts, codes of conduct are entirely voluntary and full of loopholes.

Although it is self-evidently absurd for medical professionals to look to an investor-owned company for an impartial, critical evaluation of its own products, there is ample evidence that marketing masquerading as education does increase the use of a drug; indeed, if it did not, heads would roll in executive suites, since these companies are not charities. And so why does the profession pretend to believe that drug companies, in contrast with all other businesses, can provide objective information about their own products? Unfortunately, the answer is because it pays - in CME credits, perks and free lunches. But ask yourselves, fellow physicians, why drug companies should be giving you any gifts at all, especially since they just tack the costs on to the price of drugs. The profession should pay for its own education, just as other professions do. 


\section{Influence on government}

The pharmaceutical industry has the largest lobby in Washington, DC - there are more pharmaceutical lobbyists there than members of Congress - and it gives copiously to political campaigns. ${ }^{11}$ As a result, the prescription drug legislation and policies that come out of Washington are usually made to order for the industry. Here are just a few examples:

- A series of laws has enabled drug companies to extend the exclusive marketing rights of brand-name drugs through a variety of manoeuvres, including suing generic companies, sometimes repeatedly, to gain additional 30-month periods of exclusivity.

- The fruits of publicly funded research are virtually given to drug companies, with no requirement for reasonable pricing.

- Americans are prohibited from importing prescription drugs from countries where they are less expensive, most notably Canada.

- The FDA does not require drug companies to test their new drugs against old ones for the same condition, even when several drugs of the same class are already on the market.

- Most stunningly, in 2003 Congress passed a Medicare prescription drug benefit that explicitly prohibits the agency from using its purchasing power to bargain for low prices or discounts. That makes prescription drugs unique in the Medicare program, which does regulate doctors' fees and hospital reimbursement. Furthermore, every other large insurer bargains with drug companies for lower prices or discounts, including the Veterans' Affairs System and the Department of Defense.

I won't take space to discuss some of the other excesses, such as the growing influence of drug companies on the design and reporting of clinical trials. The specific excesses already noted should be sufficient to show why prescription drug expenditures in the US are so high and so central to the struggle to contain rising health costs. Although outpatient prescriptions accounted for only $12 \%$ of US personal health care expenditures in 2002, they were its fastest growing component, increasing at an unsustainable rate of about $15 \%$ per year. ${ }^{12}$ The excesses of the pharmaceutical industry are perhaps the clearest example of the folly of allowing health care expenditures and policies to be driven by largely unregulated market forces and the profit-making imperatives of investor-owned businesses.

Marcia Angell is Senior Lecturer in Social Medicine, Harvard Medical School, Cambrige, Mass., and the author of The Truth About the Drug Companies: How They Deceive Us and What To Do About It (2004).

\section{References}

1. Pattison N, Warren L. 2002 drug industry profits: befty pharmaceutical company margins dwarf other industries. Washington (DC): Public Citizen Congress Watch; June 2003. Available: www.citizen.org/documents/Pharma_Report .pdf (accessed 2004 Nov 3).

2. Fortune 500: How the industries stack up. Fortune 2004;149(7):F26.

3. Bouton D, editor. Out-of-bounds: rising prescription drug prices for seniors. Pub no 03-106. Washington (DC): Families USA; July 2003. Available: www.familiesusa.org (accessed 2004 Nov 4).

4. Hensley S. Drug prices rise at faster clip, placing burden on consumers. Wall Street fournal 2003 Apr 15; Sect D:4.

5. US Food and Drug Administration Center for Drug Evaluation and Research, Department of Health and Human Services. NDAs approved in calendar years 1990-2003 by therapeutic potentials and chemical types. Jan 21, 2004. Available: www.fda.gov/cder/rdmt/pstable.htm (accessed 2004 Nov 3).

6. Pharmaceutical Research and Manufacturers of America (PhRMA). Pharmaceutical Industry Profile 2002. Washington (DC): PhRMA; 2002. p. 79.

7. The Henry J. Kaiser Family Foundation. Prescription drug trends: a chartbook update. Publ no 3112. Menlo Park (CA): The Foundation; 2001. p. 45. Available: www.kff.org (accessed 2004 Nov 4).

8. Mahan D. Profiting from pain: where prescription drug dollars go. Publ no 02 105. Washington (DC): Families USA; July 2002. Available: www.familiesusa.org (accessed 2004 Nov 4).

9. Harris G. As a patent expires, drug firm lines up pricey alternative. Wall Street fournal 2002 Jun 6;Sect A:1.

10. Relman A. Separating continuing medical education from pharmaceutical marketing. FAMA 2001;285:2009-12.

11. Aaron C, Lincoln T. The other drug war 2003: Drug companies deploy an army of 675 lobbyists to protect profits. Washington (DC): Public Citizen Congress Watch; June 2003. Available: www.citizen.org/documents/Other_Drug WWar2003.pdf (accessed 2004 Nov 4).

12. Levit K, Smith C, Cowan C, Sensenig A, Catlin A. Health spending rebound continues in 2002. Health Aff 2004:23:147-59. 